\title{
"Ciência da Mãe": Modos de Cuidados Clínicos com Bebês Prematuros à Luz da Teoria Psicanalítica
}

\section{"Science of the Mother": Modes of Clinical Care with Premature Babies in the Light of the Psychoanalytic Theory}

\section{"Ciencia de la Madre": Modos de Atención Clínica con Bebés Prematuros a la Luz de la Teoría Psicanalítica}

\author{
Ana Beatriz Correia Mendes ${ }^{1}$ \\ Karla Patrícia Holanda Martins \\ Universidade Federal do Ceará \\ Eleonora Pereira Melo \\ Hospital Geral César Cals e Escola de Saúde Pública do Ceará
}

\begin{abstract}
Resumo
O presente artigo tem como objetivo investigar os modos de cuidados clínicos com bebês prematuros internados em uma Unidade de Terapia Intensiva Neonatal (UTIN), à luz do referencial teórico da psicanálise, considerando os processos de instauração do sujeito e apontando para possíveis contribuições à atenção em saúde mental de bebês. A escuta psicanaliticamente orientada e as observações norteadas pelo uso do instrumento Indicadores de Risco para o Desenvolvimento Infantil (IRDI) compuseram as notas do diário de campo e permitiram a apresentação de vinhetas que ilustram a construção de possíveis dispositivos de trabalho clínico. Destaca-se a importância da sustentação de um espaço de escuta no qual se sobressaia o discurso familiar sobre o bebê, possibilitando a produção de narrativas singulares.
\end{abstract}

Palavras-chave: bebês prematuros, constituição psíquica, cuidado clínico, saúde mental, IRDI

\begin{abstract}
This article aims to investigate the clinical care modalities with premature newborn infants admitted to a Neonatal Intensive Care Unit (NICU), in the light of the theoretical framework of psychoanalysis, considering the processes of instituting the subject and pointing to possible contributions to care in mental health of babies. The psychoanalytically oriented listening and the observations guided by the use of the Risk Indicators for Child Development (IRDI) instrument compose the notes of the field diary and allowed the presentation of vignettes that illustrate the construction of possible clinical work devices. It stands out the importance of supporting the space of listening in which the familiar discourse on the baby, making possible the production of singular narratives.

Keywords: premature babies, psychic constitution, clinical care, mental health, IRDI
\end{abstract}

\section{Resumen}

El presente artículo tiene como objetivo investigar los modos de atención clínica con bebés prematuros internados en una Unidad de Terapia Intensiva Neonatal (UTIN), a la luz del referencial teórico del psicoanálisis, considerando los procesos de instauración del sujeto y apuntando para posibles contribuciones a la atención en salud mental de los bebés. La escucha psicoanalítica orientada y las observaciones orientadas por el uso del instrumento Indicadores de Riesgo para el Desarrollo Infantil (IRDI) compusieron las notas del diario de campo y permitieron la presentación de viñetas que ilustran la construcción de posibles dispositivos de trabajo clínico. Se destaca la importancia de la sustentación de un espacio de escucha en el que se sobresalía el discurso familiar sobre el bebé, posibilitando la producción de narrativas singulares.

Palabras clave: bebés prematuros, constitución psíquica, atención clínica, salud mental; IRDI

\footnotetext{
${ }^{1}$ Endereço de contato: Centro Universitário Estácio do Ceará - Unidade Via Corpvs. Coordenação do Curso de Psicologia. Rua Eliseu Uchôa Beco, 600, Água Fria, Fortaleza, CE. CEP: 60810-270. E-mail: anabeatriz.correia@hotmail.com
} 


\section{Introdução}

O Brasil é o décimo país com maior índice de partos prematuros, com cerca de 279.300 recém-nascidos (RNs) nessas condições, dos quais 12.000 morrem em decorrência de complicações neonatais (World Health Organization [WHO], March of Dimes, The Partnership for Maternal, Newborn \& Child Health [PMNCH] \& Save the Children, 2012). Ao considerar tais acontecimentos, políticas públicas foram estabelecidas para incorporar novas diretrizes ao Pacto de Redução da Mortalidade Materna e Neonatal, entre as quais se destaca a Norma de Atenção Humanizada ao Recém-Nascido de Baixo Peso - Método Canguru, instituída pela Portaria no 1683, de 12 de julho de 2007, política pública que reconhece particularidades físicas, biológicas e psicológicas do universo no qual está inserido o nascimento prematuro.

A partir dessa perspectiva, a Portaria no 930, de maio de 2012, define as diretrizes e os objetivos para a organização da atenção integral e humanizada ao recém-nascido grave, ou potencialmente grave, e garante acesso a serviços, entre os quais a assistência psicológica está incluída. Já a Lei n. 13.257, de março de 2016 (Brasil, 2016), dispõe sobre políticas públicas para a primeira infância e, em diversos trechos, discorre acerca de formas de favorecimento e criação de vínculos afetivos, além da estimulação ao desenvolvimento global da criança. Assim, tais políticas, associando a inscrição familiar desses pequenos como relevante em seu percurso de vida, assinalam os novos rumos diante do trabalho com o prematuro, marcando uma abordagem que não se limita a questões puramente orgânicas.

Diante do contexto de nascimento prematuro de um bebê - momento em que grande parte das pessoas preferem silenciar e inviabilizar lugares de fala -, a oferta de uma escuta psicanaliticamente orientada costuma revelar situações de angústia. Situações estas que, se não escutadas, poderão reverberar em acontecimentos familiares futuros. Nessa perspectiva, "o bebê, ao entrar na UTI Neonatal, precisa ser acolhido não apenas como um corpo a preencher uma vaga, mas como um sujeito que possui uma história anterior ao seu nascimento e posterior à sua internação" (Bernardino, Santos, Pedrali, \& Dio, 2012, p. 33).

Apesar do amplo debate e das intervenções clínicas realizadas a partir de estudos e teorias sobre o desenvolvimento emocional e psíquico desde a mais tenra infância, ainda há acentuado descrédito acerca da vida mental dos bebês e significativa ênfase em cuidados físicos e estimulações no ambiente hospitalar. Todavia este estudo partirá do pressuposto de que "todas as ações de seus cuidadores no primeiro ano de vida são decisivas para o seu desenvolvimento global ulterior" (Kupfer et al., 2012, p. 131).

O principal objetivo desta pesquisa foi investigar os modos de cuidados clínicos com bebês prematuros internados em uma Unidade de Terapia Intensiva Neonatal (UTIN) de uma maternidade pública, considerando-se o referencial teórico da psicanálise. Buscou-se compreender os processos de constituição psíquica do bebê, seu desenvolvimento emocional, permeado pelo discurso materno, paterno e familiar, além de apresentar possíveis contribuições dessa clínica à atenção em saúde mental de bebês prematuros por meio de vinhetas clínicas.

\section{Método}

Trata-se de uma pesquisa-intervenção que foi orientada pela abordagem qualitativa. Esta metodologia considera questões singulares, com nível de realidade que não pode ser quantificado. Foi adotada a técnica de observação participante para coleta de dados, por se 
compreender que este é um importante instrumento para o desenvolvimento dos saberes, revelando-se como um modo privilegiado de contato com o real.

Os participantes deste estudo foram recém-nascidos internados na UTIN e suas famílias. Os bebês considerados foram os nascidos com idade gestacional menor que 37 semanas, com peso abaixo de 2.500g, de acordo com o que estabelece o Ministério da Saúde do Brasil (2014). Foram elaboradas/construídas quatro vinhetas clínicas com bebês internados durante o período de abril e maio de 2016.

Optou-se por realizar esta pesquisa por considerar a situação de nascimento prematuro com efeitos na construção da subjetividade, como também por acreditar que tal nascimento possua implicações no processo de construção da parentalidade, ou seja, no modo como as relações serão construídas em torno desse bebê. As observações apresentadas neste trabaIho foram norteadas pelas indicações teóricas que embasam os Indicadores de Risco para o Desenvolvimento Infantil (IRDI), instrumento de avaliação clínica que, em linhas gerais, diz respeito à constituição psíquica dos bebês e à indicação de impasses ou questões outras que ocorram neste tempo. Os indicadores, de acordo com Lerner e Kupfer (2008), referem-se a observações do bebê na relação com as pessoas que exercem as funções maternas e paternas, o que representa um valioso e original instrumento para detecção de dificuldades de interação precoce:

O pressuposto que norteia os indicadores é o de que as bases da saúde mental se estabelecem nos primeiros anos de vida e são dependentes das relações corporais, afetivas e simbólicas que se estabelecem entre o bebê e sua mãe (ou substituto). Por isso, trata-se de investigar, por meio do IRDI o desenvolvimento da criança de um modo articulado à constituição psíquica (Kupfer et al., 2012, p. 135).

Esse instrumento contém aspectos indicativos que foram analisados e considerados relevantes para o estudo e para as observações na UTIN, tornando-se valioso para uma articulação entre a psicanálise e a neonatologia. Tal articulação esteve representada no diálogo que foi possibilitado entre os componentes da equipe que promove uma atenção em saúde mental e, consequentemente, uma intervenção precoce. Os indicadores foram organizados até a idade de 18 meses e agrupados em: 0 a 4 meses incompletos, a partir do nascimento, seja ele prematuro ou não; 4 a 8 meses incompletos; 8 a 12 meses incompletos; e 12 a 18 meses. Neste trabalho, detivemo-nos aos indicadores de 0 a 4 meses incompletos, que são os seguintes: 1. Quando a criança chora ou grita, a mãe sabe o que ela quer? 2. A mãe fala com a criança num estilo particularmente dirigido a ela (manhês)? 3. A criança reage ao manhês? 4. Há trocas de olhares entre a criança e a mãe?

Os indicadores serviram para guiar a coleta de dados, mas sua utilização não impediu a observação de outras situações clínicas consideradas relevantes para a apreensão do fenômeno. O registro foi realizado imediatamente após ou, em algumas situações, simultaneamente à sua realização, em um diário de campo que abordou as impressões acerca das situações observadas. Os dados que compuseram as vinhetas clínicas foram obtidos mediante notas registradas em diário de campo, cujo propósito foi integrar e legitimar as manifestações apresentadas e as informações presentes nos prontuários dos bebês. Silva (2013) ratifica que o intuito do diário de campo é integrar e legitimar os aspectos informais presentes na aproximação com o objeto de pesquisa. Diante disso, os sinais, as condutas e as manifes- 
tações emocionais que foram percebidos, seja na observação, seja ao longo das entrevistas, foram registrados a partir de notas escritas pela pesquisadora².

Para a realização da pesquisa, ocorreu a submissão do projeto de pesquisa ao Comitê de Ética e Pesquisa do Hospital, sob o número CAAE 53073116.6.0000.5041. Após a aprovação do referido projeto e a assinatura das participantes do Termo de Consentimento Livre e Esclarecido (TCLE), iniciaram-se tanto as observações quanto a escuta clínica.

\section{Resultados}

A rotina das mães que estão com seus bebês em UTIN resume-se a ordenhar ou retirar leite no Banco de Leite Humano a cada duas ou três horas e, em seguida, dirigir-se às unidades para ofertar o alimento. Em sua grande parte, são mulheres advindas do interior do estado e que não possuem rede de apoio familiar na capital. Algumas delas permanecem bastante tempo internadas, considerando sua situação clínica no período gestacional, e, após a alta, continuam o dia inteiro no hospital para acompanhar seus bebês, sem lugar para descanso efetivo ou para um banho, além de ficarem a serviço das demandas que emergem na UTIN.

Um desafio é criar condições de escuta ao lado da incubadora, nos corredores, nas enfermarias, no jardim do Hospital, na Sala de Parto, além de conciliar essa prática com a rotina e as urgências desse contexto. Em geral, no primeiro momento de acolhida, as famílias encontram-se sideradas, desorganizadas diante do evento repentino. Por vezes, a primeira acolhida trata de apresentar a UTIN, expor que, naquele ambiente, os pais são bem-vindos, ou seja, não são visitas, mas sim presença junto aos filhos.

A escuta psicanaliticamente orientada e a utilização do IRDI como instrumento de observação sustentaram um trabalho realizado junto a essas famílias e seus bebês, com o objetivo de promover um direcionamento pautado em uma clínica que alicerça distintos modos de cuidados clínicos. Outrossim, este trabalho busca desvelar singularidades, ratificar o desejo dos pais pelos filhos e, decerto, rearranjar o contato entre eles.

Partiremos, a seguir, para a apresentação de quatro vinhetas clínicas, a fim de delinear possibilidades de escuta nesse contexto, identificando situações que evidenciam as singularidades de cada bebê e seu entorno. Entre encontros e desencontros, foram vivências advindas dos primeiros dois meses de vida desses bebês. Após esse período, todos continuaram internados. As intervenções partiram principalmente do valor concedido ao acolhimento inicial dessas mães, para possibilitar a composição de um laço com seus filhos.

\footnotetext{
${ }^{2}$ O trabalho em uma Residência Multiprofissional é composto pelo profissional psicólogo residente, um preceptor e um orientador do Trabalho de Conclusão de Residência (TCR). Portanto a presente pesquisa foi coletada pela profissional residente em defesa do seu projeto e, por fim, apresentação de trabalho final. A preceptora foi a responsável pela orientação dentro do contexto e rotina hospitalar, no que corresponde à dinâmica do trabalho multiprofissional. A orientadora supervisionou a pesquisa no referencial teórico psicanalítico, além de outros pontos. O artigo é um recorte de uma experiência de dois anos da profissional psicóloga, financiada pelo Programa Nacional de Bolsas para os Programas de Pós-Graduação Lato Sensu, em área profissional da saúde, na modalidade Multiprofissional e Uniprofissional.
} 


\section{Situações Clínicas: O Encontro com o Inesperado}

Primeira vinheta - Mãe: Maria Aline. 22 anos. Bebê: Sofia Carla. Peso ao nascer: 820g. Idade gestacional: 25 semanas e 4 dias. Primeira filha de uma gestação inesperada. Antes de a criança nascer, a mãe permaneceu um período na Casa da Gestante em decorrência de complicações gestacionais. Ela esteve sempre presente na UTIN, atenta aos cuidados realizados pelos profissionais, mantendo uma postura vigilante. Associa essa postura a uma sensação de proteção à filha. Entende bem os aspectos médicos em relação aos cuidados por estudar na faculdade de Enfermagem, agora interrompida. Nos encontros, menciona gostar sempre de encontrar a filha com os olhos abertos, sentindo uma sensação de proteção e segurança. Ao tocar em seu bebê pela primeira vez, chora e diz que, no momento de colocá-la nos braços, vai "chorar mais ainda". Ao longo do trabalho de escuta, refere-se a uma preocupação com o cabelo da filha e diz que os profissionais nem sempre têm tal atenção, deixando-o desarrumado. Diz que isso é algo com que se preocupa. Enfatizo que essa é uma preocupação de mãe e como aquele movimento para a filha é importante, já que tem algo a ver com ela. Em sua estadia no hospital, ao ir até sua enfermaria escutá-la, sempre estava cuidando dos cabelos ou das unhas, solicitando minha presença em outros horários.

Em dado momento da internação, ocorre um agravamento do quadro médico da bebê, em decorrência da descoberta de uma complicação renal, o que dificulta o desenvolvimento da criança e faz que ela fique mais tempo necessitando da ajuda de aparelhos para respirar. Busco informações sobre o quadro clínico geral da criança com a médica de plantão, a qual, por sua vez, ratifica a gravidade e avisa que havia comunicado aos pais naquele mesmo dia, sugerindo uma dificuldade da mãe em aceitar a situação.

Presencio os pais ofertando a alimentação à filha; na ocasião, a mãe segura a sonda nasogástrica ${ }^{3}$ com o leite e interroga a bebê sobre o que está acontecendo com ela, pois parece aflita, angustiada e está muito chorosa. Tenta acalmá-la, tocando-a com firmeza, dirigindo-Ihe palavras de conforto. O pai percebe que, desde a reintubação, a filha encontra-se mais agitada e demonstrando desconforto; ele permeia o momento com palavras, dizendo à filha que está ali ao seu lado e repete: "O papai está aqui". Considerando o atravessamento pela confirmação de um diagnóstico grave e as possíveis repercussões para a filha, apenas aponto que a palavra também acalenta.

Segunda vinheta - Mãe: Fátima. 39 anos. Bebê: José Miguel. Peso ao nascer: 1.120g. Idade gestacional: 28 semanas. Primeira gestação. A mãe relata que tanto o seu relacionamento com o esposo como a vinda do bebê foram fatos inesperados em sua vida e que, devido à idade, não esperava a gravidez. Portanto o período gestacional foi permeado por preocupações e medos quanto ao risco de síndromes, do zika vírus e suas consequências para o bebê ainda desconhecidas, bem como de complicações que poderiam ser acarretadas pela gravidez considerada tardia. As primeiras notícias que recebeu sobre o filho, após o nascimento, foram transmitidas pelo seu esposo.

\footnotetext{
${ }^{3}$ Suporte alimentar em formato de tubo introduzido pela narina ou boca do bebê, que, devido ao nascimento prematuro, ainda não possui mecanismos para deglutir, respirar e sugar. Seu objetivo é facilitar a chegada do alimento ao estômago. O leite permanece em uma seringa conectada ao tubo, sendo necessário que alguém a segure para que o alimento chegue ao seu destino.
} 
Durante todos os encontros, menciona a questão do olhar, de que o olhar do seu filho "ilumina a vida" e diz algo a ela. Pergunto o que esse olhar lhe diz, e ela responde: "Que quer sair daqui, me leva embora". Nos encontros, ao lado da incubadora, demonstra preocupação e apreensão com o monitor de oxímetro (aparelho que mede a quantidade de oxigênio no sangue); apresenta-se angustiada com as baixas de saturação, isto é, com a porcentagem de oxigênio transportada pelo sangue do bebê. Diante disso, diz que sua presença é importante para monitorar e verificar se a saturação cai, podendo ajudá-lo com uma mudança de posição, caso isso aconteça. Pontuo que, para além dessa ciência técnica, dos aparelhos e das informações médicas, a sua presença é importante, e ela complementa que ali também tem a "ciência da mãe". Ratifico esta expressão utilizada por ela e a sua relevância para o processo de hospitalização que o filho enfrenta.

Queixa-se com frequência dos cuidados das técnicas de enfermagem com seu filho: para ela, algumas cuidam, enquanto outras, nem tanto. Quando toca na mão do filho, diz que ele retribui apertando e que isso é um convite para a brincadeira, principalmente nos momentos em que ela está saindo da UTIN. Revela que essa é a brincadeira preferida do filho e que esse convite ela recebe com satisfação. Aponta que cantava bastante para o filho na barriga e crê que, por esse motivo, ele reconhece a sua voz. Nos momentos junto à mãe, ao lado da incubadora, o bebê mostra-se ativo, disposto a entrar no jogo de palavras introduzido por ela, olhando-a, e, nessa ação prazerosa para ambos, a mãe retribui com um toque carinhoso. A mãe continua internada, e o pai visita diariamente Fátima e o bebê. Na presença do esposo, Fátima sorri e comenta o ciúme que sente quando o filho solta um sorriso com a chegada do pai.

Terceira vinheta - Mãe: Antônia Bárbara. 28 anos. Bebê: Luiza Glória. Peso ao nascer: 905g. Idade gestacional: 28 semanas. Segunda gestação, com um aborto anterior. Contudo, no momento, não apresenta sofrimento psíquico intenso em relação à perda do filho, que se deu ainda intraútero, na mesma quantidade de semanas do nascimento da filha. Só a conheço após alguns dias da internação de seu bebê, em decorrência dos desencontros promovidos pela atribulada rotina hospitalar. Descreve sua primeira visita ao bebê e diz ter ficado "arrasada, abalada" diante do parto precoce e também ao perceber o tamanho de sua filha. Apresenta dificuldades em realizar o toque no bebê, não conseguindo efetivá-lo até aquele momento. Quando pergunto o motivo, ela sinaliza a fragilidade do corpo do bebê. Intervenho indicando o valor do seu toque, o qual difere daquele realizado pela equipe. Por outro lado, enfatizo que esse movimento ocorrerá quando ela desejar e que, aos poucos, ela perceberá quando é possível realizá-lo.

Em outra ocasião, entusiasmada, encontra-me no corredor do hospital e narra que tocou a sua bebê e a colocou na posição canguru, destacando que se lembrou do momento em que falou sobre esse tema durante o atendimento e percebeu que foi importante tanto para a bebê quanto para ela. Essa fala marca um lugar distinto diante da filha, pois, a partir daquele momento, consegue frequentemente ofertar seu toque e seu colo.

Narra que o seu dia a dia no hospital não tem sido fácil, pois é a única responsável na família pelos cuidados com a mãe, que possui sequelas de um acidente vascular cerebral $(A V C)$. Tal fato gera preocupação e, segundo ela, interfere na retirada do leite necessário para a alimentação da filha. Encontra-se, diante disso, dividida entre os cuidados com a mãe 
e com a criança. Pontuo que é importante que a família se reorganize neste momento, porque tanto ela quanto sua bebê e sua mãe estão necessitando de cuidados e atenção, e que, naquele momento, ela está conseguindo sustentar apenas o que é viável. Sua rotina de ir para casa, não vivendo o "resguardo" - sempre referido nas maternidades -, momento do pós-parto imediato, deixa-a aflita e angustiada, uma vez que, ao chegar, após a exaustiva rotina de acompanhar a filha, presencia a ausência de cuidados com a sua mãe, o que lhe põe triste. Durante os atendimentos, ao lado da incubadora, poucas palavras são dirigidas à criança, no entanto apresenta-se com um olhar atento e, quando possível, abre as portinholas da incubadora para tocá-la.

Quarta vinheta - Mãe: Abigail. 29 anos. Bebê: Adrian. Peso ao nascer: 1.015g. Idade gestacional: 27 semanas e 6 dias. A escuta à mãe ocorreu ainda na sala de parto, quando ela sinalizou que tudo caminhava bem e tranquilamente durante a gestação, tanto consigo quanto com seu bebê, e que realizava o pré-natal de modo assíduo. O nascimento prematuro foi "inesperado". Em dado momento, coloca-se angustiada, uma vez que ainda não consegue ofertar ao filho os $2 \mathrm{~mL}$ de leite solicitados pela equipe como importantes nesse momento. Preocupa-se também com o fato de que, ao nascer, o bebê pesava $1.015 \mathrm{~g}$ e, naquele momento, está com 970g. Ela associa a perda de peso à escassez do leite, o que a deixa atormentada. Diante da situação, assinalo que o leite por vezes demora a ser produzido, principalmente quando existe o enfrentamento de uma ocasião difícil e inesperada, como um nascimento prematuro.

Pergunto como foi a escolha do nome do filho, e ela revela que foi a partir do desejo e escolha do pai, por aproximar-se de seu nome, Adriano. Relata que a avó veio visitá-lo, logo após seu nascimento, porém não adentrou na UTIN, pois não sabia da possibilidade e da permissão; conheceu-o apenas pela janela. Abigail tocou em seu bebê e conversou com o médico, o qual afirmou que, embora tenha nascido com 27 semanas, Adrian surpreendeu e respondeu bem ao tratamento realizado.

Durante o atendimento, que antecede sua ida para casa, chora bastante, e o momento da despedida, a o final do dia, é bastante complicado. Permanecer a noite sem o filho gera um aglomerado de emoções. Nesse mesmo momento de escuta, diz que os homens (referindo-se ao esposo) não entendem o que acontece entre uma mãe e um filho, mencionando o fato de o pai ter achado o filho muito pequeno.

Mãe e bebê apresentaram critérios médicos para se dirigirem à unidade de Cuidado Intermediário Neonatal Canguru (UCINCa). Vou em busca de escutá-la, pois Abigail apresenta-se chorosa e aflita, relatando que a sua estadia não está fácil, uma vez que percebe que o seu bebê não está à vontade e confortável na posição canguru. Compara com a incubadora, onde, conforme ela afirma, ele tinha maior mobilidade. Sinalizo que ali também é possível colocá-lo na incubadora em alguns momentos; ela diz saber, todavia continua afirmando que a rotina é bem distinta do que pensava.

\section{Discussões}

Ao entrar em uma Unidade de Terapia Intensiva Neonatal (UTIN), um bebê não chega sozinho: ele vem cercado de desejos e expectativas; bem antes de sua chegada real, já havia ocorrido seu advento no imaginário de seus pais (Camarotti, 2011). A família adentra na 
UTIN com questões em relação a esse filho que, por motivos diversos, chegou precocemente. Refletindo sobre esse aspecto, podemos pensar que não só o bebê é precoce, mas os genitores também se tornaram pais precocemente, pois sabemos que a gravidez não condiz apenas com um evento estritamente fisiológico, há, concomitantemente, uma gestação psíquica. Logo, diante do nascimento prematuro, algo da ordem do inesperado ocorre para os pais (Braga \& Morsch, 2003).

Ansermet (2003) associa a prematuridade e seus destinos a uma experiência traumática, descrevendo a situação de reanimação neonatal como paradigma da situação de despreparo, marcada pelo pavor, pela angústia e pela elisão da história. Conforme suas palavras:

Caímos repentinamente em um mundo desconhecido jamais imaginado, que não pode ser pensado em seus desdobramentos. Às vezes, o pavor pode inclusive apagar os sentimentos. Nada de sofrimento manifesto, nada de choro, como se as vias habituais da dor estivessem suspensas... O traumatismo conduz a uma abolição simbólica. Algumas vezes, pais e responsáveis da equipe médica não conseguem representá-lo. As coisas permanecem suspensas. Nada escora a situação. Ficamos siderados. Só podemos ser. Não se pensa. É seu furo que traumatiza. Mais tarde, será dúvida, o luto frequentemente impossível, a culpa. O irresolúvel psíquico próprio de cada um desenrola diante da criança na hiância provocada pela prematuridade. Se o trauma implica um atentado à simbolização que forma um branco, um furo, ele não cessará de se repetir, de retornar a posteriori (Ansermet, 2003, pp. 49-50).

A temporalidade na UTIN, com barulhos, aparelhos e profissionais em estado de constante alerta, colabora para certa dissipação da dimensão subjetiva, porquanto o bebê permanece em um lugar de objeto de cuidados, o que dificulta o seu reconhecimento em específico pela mãe (Zornig, Morch, \& Braga, 2004). De acordo com os pressupostos psicanalíticos, para um sujeito advir, não é suficiente apenas o investimento no seu bom funcionamento orgânico (Jerusalinsky, 2002); há, ainda, a necessidade de investimento psíquico nesse bebê, apostando que a relação com seus pais constitua seu psiquismo. Esse investimento psíquico na UTIN pode ser mediado, construído, reconstruído, interpretado e escutado, com ênfase nas relações precoces desses bebês com seus pais (Bernardino et al., 2012).

Zornig et al. (2004) partem do pressuposto de que a clínica com bebês prematuros faz uma convocação a pensarmos nos matizes da constituição subjetiva também associada à situação traumática, caracterizada, como anteriormente indicado, pela própria interrupção abrupta da gestação. Lançam ainda interrogação sobre os desafios dessa clínica diante do modo como os bebês se encontram neste estado: extremamente pequenos, pouco responsivos, e, portanto, marcados por poucos dotes de sedução e interação que facilitem a formação de vínculos.

Bowlby (2006), em seu clássico estudo sobre o apego, já demarcara possíveis consequências para o afastamento da mãe e da criança até o terceiro ano de vida, atrelando os cuidados parentais recebidos a questões de saúde mental; ou seja, uma relação calorosa, íntima e que mantenha continuidade com a mãe é essencial. Ele preconiza que a sustentação dessa relação é o alicerce para o desenvolvimento da personalidade e deve ser permeada por satisfação e prazer para ambas as partes. O autor expõe que, nesse primeiro momento, uma ruptura da relação e a privação dos cuidados maternos podem acarretar impasses, com o 
surgimento de sintomas físicos e intelectuais e de dificuldades no estabelecimento de vínculo com outras pessoas. Assim, propõe o conceito de privação para se referir à situação em que a mãe, por inúmeros motivos, torna-se impossibilitada de proporcionar cuidados de ordem amorosa ao seu filho.

Em relação ao início da vida numa incubadora, Dolto (1999) discorre sobre a importância das visitas maternas diárias, pois acredita que, mesmo do lado de dentro, a criança intui a presença materna e o desejo pela comunicação. Nessa perspectiva, é a linguagem que toma conta da cena e rearranja um elo - considerando que o recém-nascido possui a mesma percepção que lhe era viável dentro do útero. A autora propõe: "a mãe do útero é a sua mãe; a mãe que vem por ela (criança) e por si mesma (mãe), amá-la quando ela está na incubadora, também é sua mãe. Um coração a coração, na falta de um corpo a corpo" (Dolto, 1999, p. 124). Recomenda-se que profissionais assistentes que atuam nessas unidades estimulem a participação das mães, que, por vezes, sentem-se frustradas e deprimidas diante de um bebê na incubadora. Uma aposta na amamentação, quando possível, deve ser adotada como estratégia de aproximação. Dolto (1999) assinala, ainda, a importância de que, após a saída do bebê da incubadora, os pais digam-Ihe que estiveram separados por um tempo e que todos sofreram com a separação, permitindo dessa maneira que a linguagem faça a ponte entre as pessoas.

Winnicott (2006) defende a ideia de que inicialmente o neonato e sua mãe compõem uma unidade; neste primeiro momento, a relação é de dependência absoluta, o ego materno é o responsável por organizar o ego do bebê. Para o bebê, nada existe além de si, e, assim sendo, a mãe é vista como uma parte sua, hipoteticamente, uma identificação primária ocorre. 0 autor propõe que a base da individualidade também está nos primórdios do relacionamento entre a mãe e seu filho. Nessa perspectiva, o fundamento para um bebê tornar-se indivíduo, existir e ser é o contato íntimo estabelecido com a mãe, naquilo que the é possível.

\section{Do Anonimato à Aposta: O Trabalho da Equipe de Saúde na UTIN}

Possibilitar um ambiente no qual esses genitores possam se tornar pais diante do que permeia um nascimento prematuro e a internação em uma UTIN é um ponto a ser abordado. $\mathrm{O}$ primeiro olhar, o primeiro toque, o primeiro acalento a esse bebê e o primeiro ato de embalar e de segurar no colo essa criança são realizados pela equipe e compõem o cenário do seu nascimento. A equipe é responsável pela construção da ponte entre bebê e família, tendo que proporcionar condições de proximidade para que a estruturação psíquica possa ocorrer.

Este trabalho também aborda a problemática da prevenção numa perspectiva psicanalítica, localizando os possíveis provocados pelo inesperado nascimento prematuro. Faz-se uma aposta de que seria possível, desde cedo, "construir uma hipótese sobre a direção que uma construção subjetiva estaria tomando, com base no saber e na experiência que a psicanálise de crianças já acumulou" (Teperman, 2005, p. 12). Aqui há um destaque para os aspectos preventivos, no qual "prevenir faz pensar em pré-venir, pré-venir o sujeito" (TEPERMAN, 2005, p. 149, grifo do autor), antecipá-lo, realizar uma suposição, quando houve uma falha no enlaçamento com os pais no tempo da alienação.

Corroborando com essa ideia referente à prevenção, Fukuda (2014, p. 32) afirma que "prevenir - no sentido de dispor de uma antecipação - uma escuta atenta pode operar o 
giro necessário na promoção de um novo arranjo, este que seja capaz de uma significância". Todo sujeito é dotado de um mito que o antecede, uma pré-história, contida, sobretudo, no campo fantasmático materno, com marcas e experiências transcritas e retranscritas na estruturação e montagem do aparelho psíquico. Na antecipação, há, conforme já assinalado, a necessidade de que um outro antecipe que esse sujeito seja "pré-visto", "pré-dito". Desse modo, como podemos pensar a prevenção em saúde mental na primeiríssima infância? Propõe-se uma práxis de intervenção que promova "lugares e funções para que os protagonistas primordiais - outros parentais - agenciem o funcionamento do psiquismo do bebê" (Motta, 2002, pp. 114-115).

Del Volgo (1998, p. 29) intitula a sua prática como "instante de dizer", que é definido por um breve encontro fundador de acontecimentos psíquicos que permitem a criação de traços na história de quem é escutado. Revela o mito individual do sujeito sobre a urgência, a patologia e, aqui, sobre a prematuridade, permitindo produzir sentindo, reelaborar e reconstruir o encontro com o filho real, abrindo espaço para o tornar-se mãe e tornar-se pai.

Alguns aspectos que podem surgir como impasses ou atuações nesse primeiro momento entre mãe e bebê e entre bebê e família, na UTIN, são: sofrimento intenso em decorrência do afastamento precoce, em que os bebês passam a ser cuidados por uma equipe técnica (desejo anônimo), de forma que os pais não são autorizados a realizar os cuidados e a manter proximidade com o seu bebê; repercussões do encontro com o real do corpo do bebê e a constatação de sua fragilidade; o risco de morte iminente; a preocupação e a apreensão com o monitor de oxímetro; ataques constantes às pessoas da equipe; postura vigilante ao lado da incubadora; problemas na retirada e na oferta do leite; dificuldades em tocar o bebê; sentimento de culpa materno por não ter conseguido concluir a gestação; e, finalmente, os possíveis agravos e as consequências da prematuridade para o desenvolvimento global futuro dessa criança, entre outras manifestações.

Lacan (2003, p. 369), em seu texto Notas sobre a criança, refere-se à função residual exercida pela família e ao caráter irredutível da transmissão, que segue para uma ordem que não é apenas das satisfações de necessidade, "mas é de uma constituição subjetiva, implicando a relação com um desejo que não seja anônimo". O anonimato de um cuidado em uma UTIN é demonstrado em certa banalização dos cuidados prestados ao bebê. Por vezes, segurar uma sonda nasogástrica significa, para a equipe, oferecer uma dieta, em um horário previamente preconizado e desarticulado de qualquer movimento singular daquele bebê e de sua família. Os cuidados aqui são representados apenas pela funcionalidade de um corpo orgânico e pela necessidade da alimentação estritamente fisiológica.

Pensar acerca de uma atenção para aspectos psíquicos nesses primeiros momentos de vida do bebê prematuro nos remete a uma possibilidade de intervenção em saúde mental: "é uma demanda um pouco diferente da usual que chega para a saúde mental, mas não menos importante. É uma demanda que chora, um sofrimento que grita e não se faz calar. É preciso escutá-lo a tempo" (Messias, 2004, p. 60). A aposta em possibilidades de atendimento nesse estágio inicial pode minimizar efeitos e sintomas de ordem psíquica que transbordem para o desenvolvimento global da criança e que possam ocorrer em razão de um nascimento prematuro.

Em relação ao campo da atenção em saúde mental e ao trabalho do psicanalista, Priszkulnik (2009) esclarece que se trata da sustentação da diferença, da introdução do singular do su- 
jeito no universal das instituições guiadas pelo saber técnico. Aponta que há uma distinção entre o que preconiza a Organização Mundial de Saúde (OMS) a respeito do que seja saúde mental e no que a psicanálise aposta. A OMS caracteriza como um bem-estar físico, mental e social; a psicanálise questiona essa afirmativa e sugere que o mal-estar presente no viver, no dia a dia, não deve ser apagado, posto que o sofrimento é uma marca da presença do humano. Então, considerar a presença de sofrimento dentro de uma situação traumática e inesperada, como um nascimento prematuro, equivale a pensar na importância de uma atenção em saúde mental.

Ademais, a presença do psicanalista em uma UTIN, junto aos outros saberes que compõem esse cenário, é muito recente, pouco discutida, além de possuir um espaço embrionário. Diante disso, é importante construir direcionamentos para um trabalho que busque promover situações de diálogo para com a equipe e que enalteça a saúde mental nesse espaço, apontando para questões relativas à subjetividade desses bebês.

Sabe-se que a rotina de uma unidade e o panorama do sistema público de saúde correspondem a poucos leitos para assistência, precarização das condições de trabalho e escassez de profissionais que dirijam cuidados singularizados e específicos para cada bebê, seja pela pouca quantidade de trabalhadores, seja pelo fato de ainda não concederem a importância devida aos aspectos que condizem à saúde mental desses bebês. Apesar disso, a equipe pode assegurar o lugar dos pais, realizando ritos de passagem, no sentido de autorizá-los em espaços que emergem diante dos cuidados, como falar de algumas manifestações do filho enquanto esses pais não estão por perto, garantir uma troca de fralda, um toque, um cuidado.

Os pais, ao efetuarem o segurar de uma sonda, transmitem algo ao filho, melodizam, ritmam, sintonizam a voz e compõem a história daquela criança. Saem de um anonimato para uma transmissão de significância necessária, bifurcam para a marca de um interesse particularizado rumo à constituição psíquica. Nessa ação de segurar a sonda, veiculam, ao mesmo tempo, amor. Transformam necessidade em dom quando seus gestos, assim como o seu leite, são tomados por uma via simbólica, implicando um eixo de trocas. Lacan (1995, p. 192) assinala que "desde a origem, a criança se alimenta tanto de palavras quanto de pão, e perece por palavras". O importante não é o que se oferece, mas o lugar subjetivo a partir do qual algo é ofertado.

\section{Considerações Finais}

Proporcionar uma escuta, ou mesmo emprestar alguns significantes, diante do esvaziamento da palavra decorrente de um nascimento prematuro, é favorecer o processo de instauração dos sujeitos. Possibilitar que os pais teçam uma tela simbólica, um manto de palavras sobre a incubadora ou que reinventem o berço ali naquele espaço é permitir que ocorra um deslocamento do vazio para a palavra. Assim, a aposta é de que os RNs de Maria Aline, Fátima, Antônia Bárbara e Abigail - da forma como, em geral, são chamados nas unidades de neonatologia ("recém-nascido de" seguidos pelo nome da mãe), objetos de cuidados para a equipe - possam futuramente responder por Sofia Carla, José Miguel, Luiza Glória e Adrian, ultrapassando a condição de objetos e passando a de sujeitos.

Nortear observações participantes atravessadas pelo uso do IRDI cria um espaço de discussão e de intervenção com a equipe multiprofissional, enfatizando a importância da dispo- 
nibilidade de escuta e, portanto, garantindo a invenção de diferentes sentidos sobre o acontecimento do nascimento prematuro. Do mesmo modo, promove um trabalho de atenção em saúde mental a bebês, ainda incipiente nesse ambiente, implicando e responsabilizando cada agente de cuidados na produção de modos de atenção que objetivem a tessitura de um laço do bebê com os seus semelhantes.

Criar modos de cuidados clínicos à luz da teoria psicanalítica é autorizar, em meio aos cuidados técnicos e as nuances da saúde pública, a "ciência da mãe". Trata-se de reinventar um espaço de escuta, permitindo o desvelar da sabedoria materna, por vezes suspensa e colocada em parênteses nesse contexto; sustentar um espaço de fala em que o discurso familiar distancia-se de direcionamentos e verdades universais acerca do bebê, bem como, em outra via, promove a produção de narrativas singulares. Posteriormente, é esse saber que bordará o que foi vivenciado nesse período, permitindo à criança um lugar no social, na cultura, distante do determinismo biológico da prematuridade, respondendo em nome próprio e sendo autora de sua história.

\section{Referências}

Ansermet, F. (2003). Clínica da origem: A criança entre a medicina e a psicanálise (D. A. Seidl, Trad.). Rio de Janeiro: Contra Capa Livraria.

Bernardino, L. M., Santos, C. C., Pedrali, C. B., M. \& Dionísio, M. W. S. (2012). A escuta psicanaliticamente orientada em uma UTI Neonatal. In M. C. M. Kupfer, L. M. Bernardino, \& R. M. M. Mariotto (Orgs.), Psicanálise e ações de prevenção na primeira infância (pp. 29-46). São Paulo: Escuta/Fapesp.

Bowlby, J. (2006). Cuidados maternos e saúde mental (5a ed., V. L. B. Souza \& I. Rizzini, Trad.). São Paulo: Martins Fontes. (Trabalho original publicado em 1976)

Braga, N. A., \& Morsh, D. S. (2003). Maternagem ampliada. In M. E. L. M. Moreira, N. A. Braga, \& D. S. Morsh (Orgs.), Quando a vida começa diferente: O bebê e sua família na UTI Neonatal (pp. 81-95). Rio de Janeiro: FIOCRUZ.

Brasil. (2007, 12 de Julho). Portaria n. 1683. Aprova, na forma do Anexo, a Norma de Orientação para a Implantação do Método Canguru. Diário Oficial da União, n. 134.

Brasil. (2012, 10 de Maio). Portaria n. 930. Define as diretrizes e objetivos para a organização da atenção integral e humanizada ao recém-nascido grave ou potencialmente grave e os critérios de classificação e habilitação de leitos de Unidade Neonatal no âmbito do Sistema Único de Saúde (SUS). Diário Oficial da União, n. 91.

Brasil. (2014). Manual AIDPI Neonatal: Quadro de procedimentos (5a ed.). Brasília: Ministério da Saúde. Disponível em http://migre.me/sFb2d .

Brasil. (2016, 9 de Março). Lei n. 13.257, de 8 de Março de 2016. Dispõe sobre as políticas públicas para a primeira infância e altera a Lei n. 8.069, de 13 de julho de 1990 (Estatuto da Criança e do Adolescente), o Decreto-Lei n. 3.689, de 3 de outubro de 1941 (Código de Processo Penal), a Consolidação das Leis do Trabalho (CLT), aprovada pelo Decreto-Lei n. 5.452, de 1 o de maio de 1943, a Lei n. 11.770, de 9 de setembro de 2008, e a Lei n. 12.662, de 5 de junho de 2012. Diário Oficial da União, seção 1.

Camarotti, M. C. (2011). De braços vazios: Uma separação precoce. In C. M. F. Rohenkohl (Org.), A clínica com o bebê (pp. 49-62). São Paulo: Casa do Psicólogo. 
Del Volgo, M-J. (1998). O instante de dizer: O mito individual do doente sobre a medicina moderna. São Paulo: Escuta.

Dolto, F. (1999). Tudo é linguagem (2a ed., L. Machado, Trad.). São Paulo: Martins Fontes. (Trabalho original publicado em 1987).

Fukuda, J. E. (2014). Considerações a respeito da prevenção em saúde mental na primeira infância. In M. C. M. Kupfer, \& R. M. M. Mariotto (Orgs.), De bebê a sujeito: A metodologia IRDI nas creches (pp. 25-32). São Paulo: Escuta/Fapesp.

Jerusalinsky, A. N. (2002). O nascimento do ser falante. In L. M. Bernardino, \& C. M. F. Rohenkohl (Orgs.), O bebê e a modernidade: Abordagens teórico-clínicas. São Paulo: Casa do Psicólogo.

Kupfer, M. C. M., Bernardino, L. M. F., Mariotto, R. M. M., Pesaro, M. E., Lajonquière, L. de, Voltolini, R., \& Machado, A. M. (2012). Metodologia IRDI: Uma ação de prevenção na primeira infância. In M. C. M. Kupfer, L. M. Bernardino, \& R. M. M. Mariotto (Orgs.), Psicanálise e ações de prevenção na primeira infância (pp. 131-145). São Paulo: Escuta/Fapesp.

Lacan, J. (1995). O seminário, livro 4: A relação de objeto (D. D. Estrada, Trad.). Rio de Janeiro: Zahar. (Trabalho original publicado em 1956-1957)

Lacan, J. (2003). Nota sobre a criança. In J. Lacan. Outros escritos (pp. 369-370, V. Ribeiro, Trad.). Rio de Janeiro: Jorge Zahar. (Trabalho original publicado em 1969).

Lerner, R., \& Kupfer, M. C. (Orgs.). (2008). Psicanálise com crianças: Clínica e pesquisa. São Paulo: Escuta.

Messias, C. O. (2004). A clínica com bebês e seus pais: Uma experiência na saúde pública. In T. Ferreira (Org.), A criança e a saúde mental: Enlaces entre a clínica e a política. Belo Horizonte: Autêntica/FCH-FUMEC.

Motta, S. P. P. (2002). Prevenção em saúde mental - por que não? In L. M. F. Bernardino, \& C. M. F. Rohenkohl (Orgs.), O bebê e a modernidade: Abordagens teórico-clínicas (pp. 109116). São Paulo: Casa do Psicólogo.

Priszkulnik, L. (2009). Prevenção: Saúde mental e psicanálise. In Formação de profissionais e a criança-sujeito, 7, colóquio LEPSI/FE-USP, mesas redondas prevenção: O há de vir do sujeito. [on-line]. Disponível em http://www.proceedings.scielo.br/scielo. php?script=sci_arttext\&pid=MSC0000000032008000100002\&lng=en\&nrm=iso

Silva, D. Q. (2013). A pesquisa em psicanálise: O método de construção do caso psicanalítico. Estudos de Psicanálise, 39, 37-46.

Teperman, D. W. (2005). Clínica psicanalítica com bebês: Uma intervenção a tempo. São Paulo: Casa do Psicólogo/Fapesp.

Winnicott, D. W. (2006). Os bebês e suas mães (3a ed., J-L. Camargo, Trad.). São Paulo: Martins Fontes. (Trabalho original publicado em 1988).

World Health Organization, March of Dimes, The Partnership for Maternal, Newborn \& Child Health, \& Save the Children. (2012). Born too soon: The global action report on preterm birth. Geneva. Disponível em https:// apps.who.int/iris/bitstream/handle/10665/44864/9789241503433_eng. pdf;jsessionid=27202FFC5F972FAC80C0343B42AD6D04 ?sequence $=1$

Zornig, S. M. A-J., Morsch, D. S., \& Braga, N. A. (2004). Parto prematuro: Antecipação e descontinuidade temporal? I R. O. de. Aragão (Org.), O bebê, o corpo e a linguagem (pp. 165-174). São Paulo: Casa do Psicólogo. 
Recebido: 06/03/2018

Última revisão: 27/11/2018

Aceite final: 27/02/2019

Sobre as autoras:

Ana Beatriz Correia Mendes - Psicóloga graduada pela Universidade de Fortaleza (UNIFOR). Especialista em Residência Integrada em Saúde com Ênfase em Neonatologia, tendo como Instituição Executora o Hospital Geral Dr. César Cals (HGCC) e como Instituição Formadora a Escola de Saúde Pública do Ceará (ESP/CE). Mestranda em Saúde da Mulher e da Criança pela Universidade Federal do Ceará (UFC). Preceptora de Estágios do Centro Universitário Estácio do Ceará. E-mail: anabeatriz.correia@hotmail.com, Orcid: http://orcid.org/0000-0003-3915-5221

Karla Patrícia Holanda Martins - Pós-doutora em Psicologia Clínica pelo Instituto de Psicologia da Universidade de São Paulo (USP). Doutora em Teoria Psicanalítica (UFRJ). Professora associada da Graduação e Pós-Graduação em Psicologia da Universidade Federal do Ceará (UFC). E-mail: kphm@uol.com.br, Orcid: https://orcid.org/0000-0003-3242-6287

Eleonora Pereira Melo - Psicóloga e Mestre em Psicologia pela Universidade Federal do Ceará. É psicóloga da UTI Neonatal do Hospital Geral César Cals (HGCC), preceptora de Psicologia e docente da Residência Integrada em Saúde pela Escola de Saúde Pública do Ceará (RIS-ESP/CE), com Ênfase em Neonatologia. E-mail: eleonorapsi@gmail.com, Orcid: https://orcid.org/0000-0002-9731-5134 